\title{
The Lancet Commission on Dementia Prevention, Intervention, and Care: a call for action
}

\author{
V. Orgeta*, N. Mukadam, A. Sommerlad and G. Livingston \\ Division of Psychiatry, University College London, London, UK
}

\begin{abstract}
The purpose of this Editorial is to summarise the key recommendations of the Lancet Commission on Dementia Prevention, Intervention, and Care, reporting on the best available evidence to date on what we can do to prevent and intervene for dementia. We briefly describe the new life-course model of dementia prevention incorporating nine modifiable risk factors and their potential effect in reducing individuals' risk of dementia. We also summarise the recommendations of the report about which pharmacological, psychological, and social interventions are effective, and improve outcomes for people with dementia and their families. Recent developments highlight that there is good potential for the prevention of dementia. Progress in evidence-based approaches indicate the potential for dementia care to be of high-quality and widely accessible. Acting upon this knowledge now will reduce the global burden of dementia and improve the lives of people living with dementia and their families.
\end{abstract}

Received 19 October 17; Revised 17 January 18; Accepted 22 February 18

Key words: Alzheimer's disease, care, dementia, intervention, prevention.

Dementia is a clinical syndrome characterised by a decline from a previously attained cognitive level affecting a person's activities of daily living and social functioning. Alzheimer's disease is the commonest cause of dementia, followed by vascular dementia, dementia with Lewy bodies, and frontotemporal dementia. Globally there were $\sim 47$ million people living with dementia in 2015, a number expected to rise to 131 million by 2050 (Prince et al. 2015) primarily driven by increased longevity. The World Health Organisation's (2017) Global Action Plan identifies dementia as a global priority urging key stakeholders to put in place necessary policies and resources that would ensure priority 'to action in dementia'. The Lancet Commission on Dementia Prevention, Intervention, and Care provides an evidence-driven report that can act as a vehicle for implementing specific interventions for the prevention and management of dementia (Livingston et al. 2017).

The aim of the report was to consolidate the evidence base through the involvement of experts from a variety of disciplines and countries and add to it. The specific recommendations are about transforming the lives of people with dementia and their families through prevention, intervention, and care. The full report can be accessed here: http://www.thelancet.com/journals/ lancet/article/PIIS0140-6736(17)31363-6/fulltext. For this editorial we summarise the key recommendations

* Address for correspondence: Dr V. Orgeta, Senior Fellow Alzeimer's Society, Division of Psychiatry, University College London, 6th Floor, Maple House, 149 Tottenham Court Road, London W1T 7NF, UK. (Email: v.orgeta@ucl.ac.uk) of the Commission into two main categories; those related to prevention, and those related to intervention and care.

\section{Prevention of dementia recommendations}

The number of people with dementia is increasing globally, especially in low- and middle-income countries (Prince et al. 2015). Recent studies suggest that changes have been occurring, with decreases in the agespecific incidence or prevalence in the United States, United Kingdom, Sweden, the Netherlands, France, and Canada, probably reflecting reduced exposure to risk factors or increased resilience to cognitive decline, but in others, for example, Japan and China this is not the case (Chan et al. 2013; Okamura et al. 2013). Identifying and modifying risk could translate to a huge benefit for societies, individuals, and health care systems. Prevention is always preferable to cure but this is particularly important in view of the absence of disease modifying treatments of the underlying illness. Any delay in the onset of dementia will be associated with significant health gains for individuals and society.

The Lancet Commission extends our knowledge of dementia prevention by calculating and presenting a new model approach to modifiable risk factors (Livingston et al. 2017). This model estimates the population attributable fraction, which is the proportional (percentage) reduction in new cases of dementia that would occur if specific risk factors were completely eliminated. The risk factors included in this model are those identified by the UK National Institute of Health and Care 
Table 1. Potentially modifiable risk factors for dementia

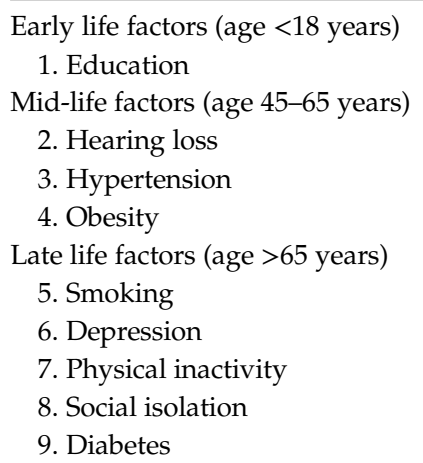

Excellence (2015) and the US National Institutes of Health (NIH) (Daviglus et al. 2010) guidelines, with those qualifying on 'best-quality evidence' being added. What is new and important about this model is that it takes a life-course approach to dementia prevention, considering that risk factors and their contribution to risk of dementia differ across the life span, and additionally calculates the contribution of emerging risk factors that have not been considered before - hearing loss and social isolation. These nine risk factors were education (the effect of which is mostly in early life), hearing loss, hypertension, and obesity (mid-life) and late life factors specifically smoking, depression, physical inactivity, social isolation, and diabetes (see Table 1).

This new model found that more than a third of dementia cases are potentially preventable with collectively all nine factors accounting for $35 \%$ of the population dementia risk. Although it is impossible to completely eliminate these risks, the evidence of incidence reductions to date of around $20 \%$ strongly suggests that preventive strategies have the potential to delay or prevent dementia. Fig. 1 shows the Lancet Commission life-course model of the nine key modifiable risk factors to dementia, delineating each factor's contribution.

We were surprised to find that hearing loss was the largest contributor. This was accounted for by the strength of the association with dementia, almost doubling the risk, and by how common hearing loss is. Overall, we found that the most promising intervention targets were increasing education in early life, increasing physical activity and social engagement, reducing smoking, treating hypertension, diabetes, and hearing impairment. These are unlikely to be harmful and would also benefit people in other ways.

\section{Recommendations for intervention and care for people with dementia and their families}

Diagnosis is a prerequisite for accessing interventions, and therefore we view timely diagnosis as the vehicle to

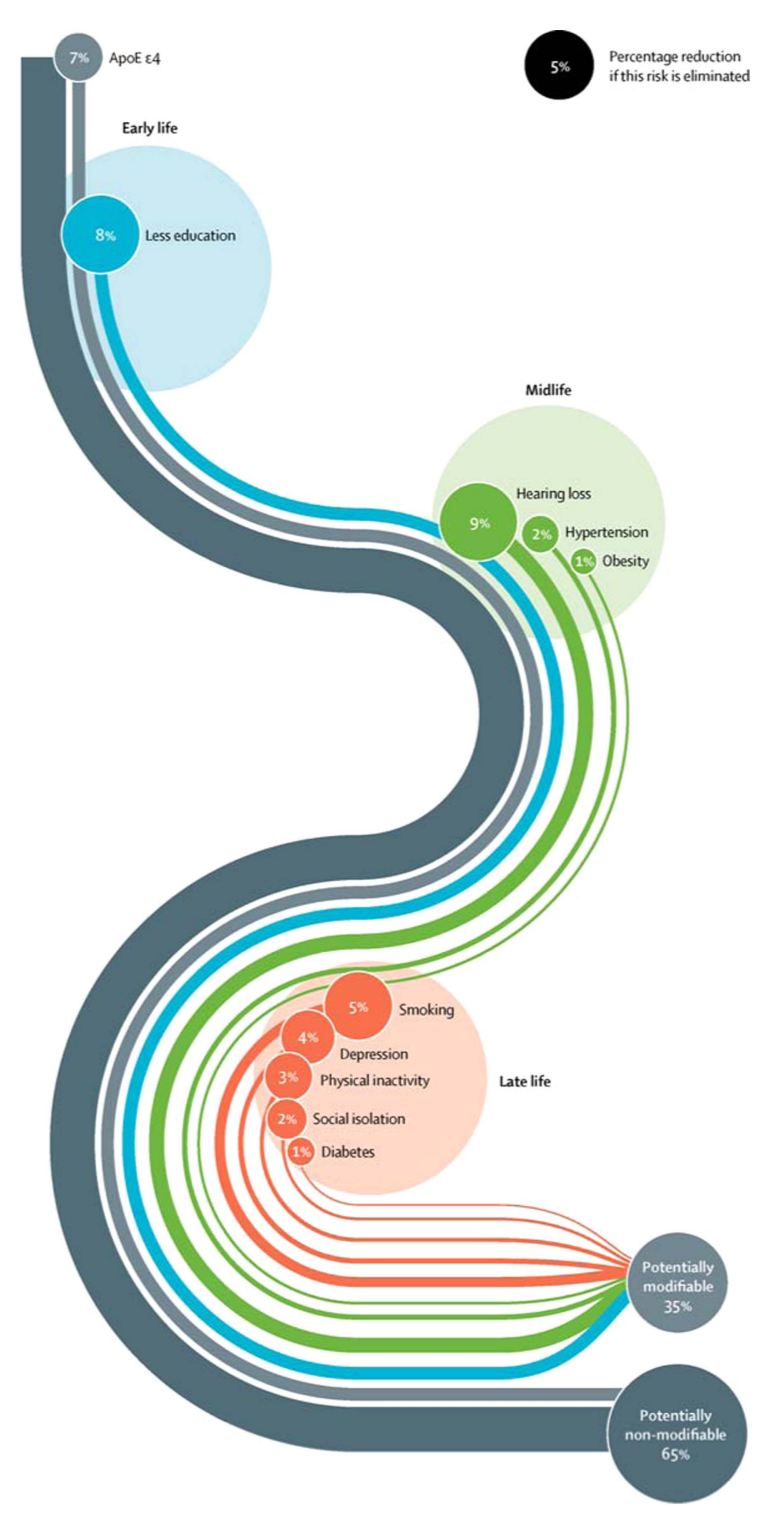

Fig. 1. Life-course model of contribution of modifiable risk factors to dementia.

accessing timely care (for further information on early diagnosis see the full Lancet Commission report; Livingston et al. 2017). The Commission emphasises that although the underlying illness is not curable, many of the symptoms of dementia are now manageable, therefore the course of dementia and its symptoms changes with good dementia care. In the section below we review interventions that are effective and improve outcomes for people with dementia and their families, and should therefore be implemented now.

The report highlights that good dementia care is individualised, which means that people with dementia and their families need to have their medical, social, and supportive care needs assessed and re-assessed over time as they change. They should be tailored to individual's cultural needs, preferences, and priorities. 
Cholinesterase inhibitors are in routine use for treating cognitive symptoms, and although they do not change the neuropathology of the disease, they have a small but clinically important effect on cognition and function at all Alzheimer's disease severities (Birks, 2006), and are also effective in dementia with Lewy bodies (McKeith et al. 2000). Optimal doses also benefit global change and activities of daily living (Birks, 2006).

Family carers of people with dementia are at increased risk of experiencing depression, with $\sim 40 \%$ being at increased risk of developing clinically significant symptoms of depression and anxiety (Mahoney et al. 2005). Treating carers' psychological distress and specifically depression is important for the individual and in addition, the presence of carer distress predicts care breakdown, admission to home care (Gallagher et al. 2011), and increases risk of elder abuse (Cooper et al. 2010). There are effective interventions such as the STrAtegies for RelaTives (START) (Livingston et al. 2013) or the Resources for Enhancing Alzheimer's Caregiver Health intervention (REACH) (Gitlin et al. 2003), which reduce risk of depression for carers and should therefore be made available. People with dementia and their families also need opportunities to discuss their views on plans about the future, considering the loss of capacity associated with more severe dementia. Health care professionals should discuss these views at an early stage to maximise the involvement of people with dementia.

Neuropsychiatric symptoms in dementia are common, affecting nearly every individual at some point in the illness. They increase severity of dementia symptoms and distress experienced by family carers and often mean that care at home breaks down (Savva et al. 2009). These symptoms can have many causes and often several cluster together therefore their careful assessment is important (Lyketsos et al. 2001). The Commission published algorithms incorporating strategies for managing neuropsychiatric symptoms of dementia particularly agitation, low mood, and psychosis which is usually psychological, social, and environmental, with pharmacological management restricted to people who experience severe symptoms. An important contribution of the Commission is the provision of guidance for clinicians and professionals involved in the care of people with dementia, describing the key principles and approaches to assessment and management of each of these symptoms (Livingston et al. 2017).

The report highlighted that people with dementia are vulnerable to risks including self-neglect, vulnerability (including to exploitation), managing money, driving, or using weapons (Cooper et al. 2008; Cooper \& Livingston, 2014). Risk assessment and management at all stages is essential, balancing severity of risk against the person's right to autonomy. Given that dementia shortens life span, and a third of older people die with dementia, the Commission recommends that professionals working in end-of-life care consider whether a patient has dementia, as they might be unable to make decisions, or express their needs and wishes. Technological interventions have the potential to improve care, assisting people with dementia to live in safe and stimulating environments, but caution is needed so that these interventions are for specific benefit rather than to replace social contact.

\section{Conclusions}

This editorial has reviewed the key messages of the Lancet Commission on Dementia, placing an emphasis on what we can do now to prevent and intervene for dementia. In summary, the Commission's key findings show that a large proportion of dementia is preventable and 'acting now' will have a huge benefit for societies and individuals worldwide. An important life-course approach, accommodating exposure to specific risk factors across the life span is presented, and urges us to think that 'it is never too early and never too late' to prevent dementia. The report also addresses the significant developments in interventions that improve outcomes for people with dementia and their families which should be routinely offered. This means we have made significant progress and are much closer to safe, widely accessible, high-quality dementia care.

\section{Acknowledgements}

For the Lancet Commission on Dementia Prevention, Intervention, and Care report, we were partnered with University College London, and received financial support from the Alzheimer's Society (AS), UK, the Economic and Social Research Council (ESRC), and Alzheimer's Research UK (ARUK). The Lancet commission received financial support from the AS, ESRC and ARUK. Vasiliki Orgeta is funded by the Alzheimer's Society. N.K. is funded by the National Institute for Health Research (DRF-2012-05-141). A.S. is funded by the Welcome Trust. All authors are supported by the UCLH NIHR Biomedical Research Centre. G.L. was (in part) supported by the National Institute for Health Research (NIHR) Collaboration for Leadership in Applied Health Research and Care (CLAHRC) North Thames at Bart's Health NHS Trust. The views expressed are those of the author(s) and not necessarily those of the NHS, the NIHR, or the Department of Health.

\section{Financial Support}

This article received no specific grant from any funding agency, commercial, or not-for-profit sectors. 


\section{Conflicts of Interest}

None.

\section{Ethical Standards}

The author asserts that all procedures contributing to this work comply with the ethical standards of the relevant national and institutional committee on human experimentation with the Helsinki Declaration of 1975, as revised in 2008.

\section{References}

Birks J (2006). Cholinesterase inhibitors for Alzheimer's disease. The Cochrane Database of Systematic Reviews 1, CD005593.

Chan KY, Wang W, Wu JJ, Liu L, Theodoratou E, Car J, Middleton L, Russ TC, Deary IJ, Campbell H, Wang W, Rudan I, Global Health Epidemiology Reference Group (GHERG) (2013). Epidemiology of Alzheimer's disease and other forms of dementia in China, 1990-2010: a systematic review and analysis. Lancet (London, England) 381, 2016-2023.

Cooper C, Livingston G (2014). Mental health/psychiatric issues in elder abuse and neglect. Clinics in Geriatric Medicine 30, 839-850.

Cooper C, Selwood A, Blanchard M, Walker Z, Blizard R, Livingston G (2010). The determinants of family carers' abusive behaviour to people with dementia: results of the CARD study. Journal of Affective Disorders 121, 136-142.

Cooper C, Selwood A, Livingston G (2008). The prevalence of elder abuse and neglect: a systematic review. Age and Ageing 37, 151-160.

Daviglus ML, Bell CC, Berrettini W (2010). NIH state-of-thescience conference statement: preventing Alzheimer's disease and cognitive decline. NIH Consensus and State-OfThe-Science Statements 27, 1-30.

Gallagher D, Ni Mhaolain A, Crosby L, Ryan D, Lacey L, Coen RF, Walsh C, Coakley D, Walsh JB, Cunningham C, Lawlor BA (2011). Determinants of the desire to institutionalize in Alzheimer's caregivers. American Journal of Alzheimer's Disease and Other Dementias 26, 205-211.

Gitlin LN, Belle SH, Burgio LD, Czaja SJ, Mahoney D, Gallagher-Thompson D, Burns R, Hauck WW, Zhang S, Schulz R, Ory MG, REACH Investigators (2003). Effect of multicomponent interventions on caregiver burden and depression: the REACH multisite initiative at 6-month follow-up. Psychology and Aging 18, 361-374.
Livingston G, Barber J, Rapaport P, Knapp M, Griffin M, King D, Livingston D, Mummery C, Walker Z, Hoe J, Sampson EL, Cooper C (2013). Clinical effectiveness of a manual based coping strategy programme (START, STrAtegies for RelaTives) in promoting the mental health of carers of family members with dementia: pragmatic randomised controlled trial. BMJ (Clinical research ed.) $347, \mathrm{f} 6276$.

Livingston G, Sommerlad A, Orgeta V, Costafreda SG, Huntley J, Ames D, Ballard C, Banerjee S, Burns A, Cohen-Mansfield J, Cooper C, Fox N, Gitlin LN, Howard R, Kales HC, Larson EB, Ritchie K, Rockwood K, Sampson EL, Samus Q, Schneider LS, Selbaek G, Teri L, Mukadam N (2017). Dementia prevention, intervention, and care. Lancet (London, England) 390, 2673-2734.

Lyketsos CG, Sheppard JM, Steinberg M, Tschanz JA, Norton MC, Steffens DC, Breitner JC (2001). Neuropsychiatric disturbance in Alzheimer's disease clusters into three groups: the Cache County study. International Journal of Geriatric Psychiatry 16, 1043-1053.

Mahoney R, Regan C, Katona C, Livingston G (2005). Anxiety and depression in family caregivers of people with Alzheimer disease: the LASER-AD study. The American Journal of Geriatric Psychiatry 13, 795-801.

McKeith I, Del Ser T, Spano P, Emre M, Wesnes K, Anand R, Cicin-Sain A, Ferrara R, Spiegel R (2000). Efficacy of rivastigmine in dementia with Lewy bodies: a randomised, double-blind, placebo-controlled international study. Lancet (London, England) 356, 2031-2036.

National Institute of Health and Care Excellence (2015). Dementia, disability and frailty in later life-mid-life approaches to delay or prevent onset. NICE: London.

Okamura H, Ishii S, Ishii T, Eboshida A (2013). Prevalence of dementia in Japan: a systematic review. Dementia and Geriatric Cognitive Disorders 36, 111-118.

Prince M, Wimo A, Guerchet M, Ali GC, Wu YT, Prina M (2015). World Alzheimer report 2015-the global impact of dementia: an analysis of prevalence, incidence, cost and trends. Alzheimer's Disease International: London.

Savva GM, Zaccai J, Matthews FE, Davidson JE, McKeith I, Brayne C, Medical Research Council Cognitive Function and Ageing Study (2009). Prevalence, correlates and course of behavioural and psychological symptoms of dementia in the population. The British Journal of Psychiatry 194, 212-219.

World Health Organisation (2017). Draft global action plan on the public health response to dementia. Report by the Director-General, WHO, 3 April, Geneva. 